\title{
From PID to Nonlinear State Error Feedback Controller
}

\author{
Wameedh Riyadh Abdul-Adheem \\ Electrical Engineering Department \\ College of Engineering, Baghdad University \\ Baghdad, Iraq
}

\author{
Ibraheem Kasim Ibraheem \\ Electrical Engineering Department \\ College of Engineering, Baghdad University \\ Baghdad, Iraq
}

\begin{abstract}
In this paper an improved nonlinear state error feedback controller (INLSEF) has been proposed for perfect reference tracking and minimum control energy. It consists of a nonlinear tracking differentiator together with nonlinear combinations of the error signal. The tracking differentiator generates a set of reference profile for the input signal, which is the signal itself in addition to its derivatives. On the other hand, the 12-parameters nonlinear combinations of the error signal make the INLSEF controller can handles with time-varying and system's nonlinearity. Digital simulation studies have been conducted for the proposed controller and compared with several works from literature survey on two case studies, mass-springdamper which is a very nonlinear system and nonlinear ball and beam systems. The parameters of the nonlinear combination of the error signal are tuned to satisfy the optimality condition by minimizing the OPI performance index defined in this work. From the simulations results one can conclude that the proposed INLSEF controller performance is better than that of its counterpart in terms of speed and control energy and minimum error. Also, the results showed that the proposed controller is effectively enhancing the stability and performance of the closed loop system.
\end{abstract}

Keywords-tracking differentiator; state error feedback; Lyapunov function; asymptotic stability; nonlinear PID

\section{INTRODUCTION}

The proportional-integral-derivative (PID) control algorithm has been being widely used in many industrial process control applications. Due to its simple structure, easy tuning and effectiveness, this technology has been being the tool of choice for so long among practicing engineers; Today, PID control algorithm is used in over $95 \%$ of industrial applications. In addition to PID, classical control theory provided additional control blocks such as lead and lag compensators that further enhanced the performance of this error-based control law.

Although its popularity and long term, applied experience shows that the PID technology itself has limitations and shortages as follows, The regular PID control action: $u=$ $k_{p} e+k_{i} \int e d t+k_{d} \frac{d e}{d t}$ is based on linear combination of the current (P), past (I) and future (D) of the error. The linear combination is not the best one which corresponds to speedily of system response. Secondly, the differential part of the control signal is sensitive to noise. Last but not the least, the input signal $e(t)$ is not smoothly even non-continuous. It is not reasonable that the error $\mathrm{e}(\mathrm{t})$ is directly used without any pre- processing in PID algorithm. Finally, the integral part of $u(t)$ is used for eliminating the steady error. But at the same time, it's probably leads to instability of system.

The nonlinear PID controllers are classified into two broad classes according to how the state is affecting the gain. In the first class, the controller gain is directly related to the magnitude of the state, and the second class uses the phase of the state as the parameter to modify the gain of these controllers.

Several applications for NPID controller includes: control of quad-rotor UAV [1], twin rotor MIMO system [2], motion systems [3], and pneumatic actuator system [4]. The Marroquin nonlinear controller in [5] was experimentally demonstrated to give better performance than standard linear control. Han in [6] proposed a control law which could improve the dynamic response velocity, veracity, and robustness of the controlled plant. A nonlinear algorithm was employed in [7] by Huang to realize the nonlinear control for the purpose of enhancing transient stability of the model to be controlled. A nonlinear controller is suggested by $\mathrm{Su}$ in 2005 which enhances the performance of the standard linear PID controller [8]. The PID controllers are also combined with fuzzy logic [9-12], neural networks [13-16], or implemented based on fractional order [17-19].

This paper proposes a nonlinear controller known as Improved nonlinear state error feedback controller. The proposed controller derived by combining the nonlinear gains and the PID with a modified structure that includes tracking differentiators. A nonlinear tracking differentiator is used to estimate the plant states, which are required by the nonlinear controllers. The nonlinear tracking differentiator is chosen to attain a high robustness against noise and generate a highquality differential signal. The controllers has been simulated and tested on two case studies (nonlinear mass-spring-damper and nonlinear ball and beam) in order to investigate their performance in terms of tracking. For the purpose of comparison, the same simulations and experiments are repeated for both types of controller subject to the same data applied to the set-point.

The paper is organized as follows: section II includes the problem statement. Next, in section III a nonlinear controller is presentation. In section IV, the improved nonlinear state error feedback controller structure and mathematical model is completely described, which is followed by a bunch of tested nonlinear SISO plants in section V. A numerical simulation 
and results discussion example in section VI. Conclusion and remarks are given in section VII.

\section{PROBLEM STATEMENT}

Consider the following nonlinear control plant model:

$$
\begin{aligned}
& x^{(n)}=f\left(x, \dot{x}, \ldots, x^{(n-1)}\right)+g(x) u \\
& y=x
\end{aligned}
$$

where $x^{(n)}$ is the state vector; $y$ is the measured output variable; $u$ is the scalar control input. The control problem is to provide asymptotical stability of the closed system. In addition, it is necessary to provide the desired quality of the transient processes at the output $y(t)$ of system (1) with minimum control effort and reduction in the chattering phenomenon.

\section{THE NONLINEAR STATE FEEDBACK CONTROLLER}

The nonlinear PID (NPID) control has found two broad classes of applications:

1) Nonlinear systems, where NPID control is used to accommodate the nonlinearity, usually to achieve consistent response across a range of conditions.

2) Linear systems, where NPID control is used to achieve performance not achievable by a linear PID control, such as increased damping, reduced rise time for step or rapid inputs, improved tracking accuracy [8].

In this paper, an INLSEF control method with a tracker of differential (TD) is proposed to obtain a low-noise and precise derivative of a specific nonlinear input signal.

With respect to the shortcomings mentioned previously, the possible solutions could be as follows:

1) Tracking differentiator (TD) could be designed so that de/dt would be obtained in a precise way.

2) Appropriate nonlinear control algorithm could be applied [7].

The proposed control scheme is shown in Figure 1 and is described in more details in the subsequent sections.

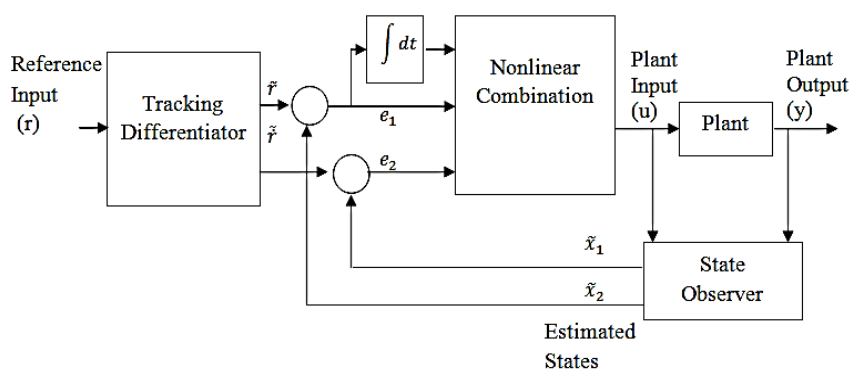

Fig. 1. The nonlinear state error feedback controller

\section{Lemmas 1:}

Consider the observable $n$-th order SISO nonlinear control system in (1) With PD controller, $u=k_{p} e+k_{d} \dot{e}$, which is given in Fig. 2 (a). If the system is linearizable (in the sense of Taylor approximation) then the linear control law $u$ could be written in the general form $u=\Psi(e)$ as shown in figure $2(\mathrm{~b})$. Such that $\Psi$ is sector bounded and satisfy $\Psi(0)=0$.

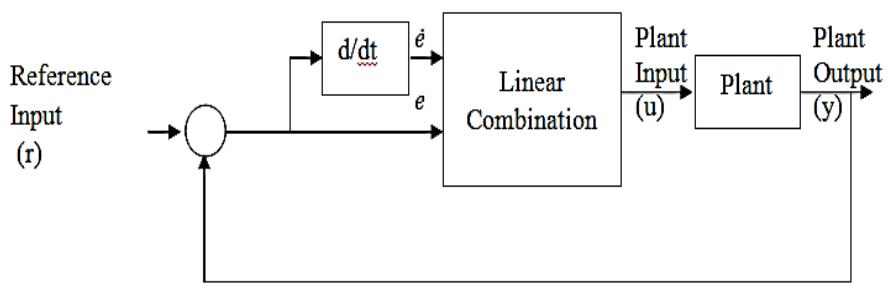

(a)

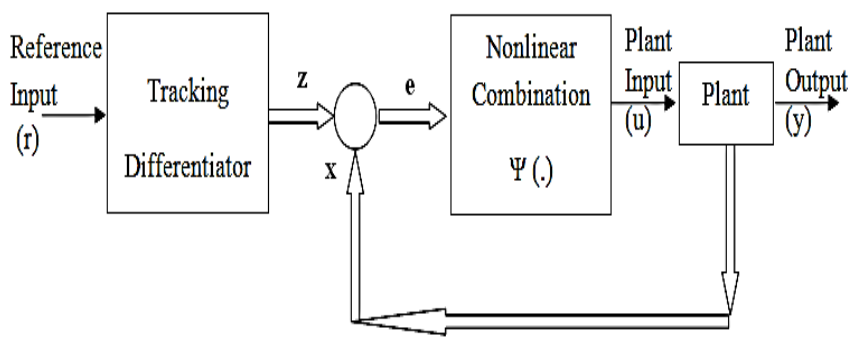

(b)

Fig. 2. The SISO system in lemma 1, (a) Linear combination control law, (b) Nonlinear combinational control law

\section{Proof:}

Without loss the generality; consider the following second order nonlinear system

$$
\begin{aligned}
& \ddot{x}=f(x, \dot{x})+g(x) u \\
& y=x
\end{aligned}
$$

Because the system is linearizable then $g(x)=b$; where $b$ is $2 \times 1$ vector with constant entries. The control law with the conventional PD controller has the following formula

$$
u=k_{p} e+k_{d} \dot{e}
$$

where $e=r-y$. By considering $x_{1}=x, \dot{x}_{1}=x_{2}$, then system in (1) can be represented as:

$$
\begin{aligned}
& \dot{x}_{1}=x_{2} \\
& \dot{x}_{2}=f\left(x_{1}, x_{2}\right)+b u \\
& y=x_{1}
\end{aligned}
$$

Also, consider the general formula for a finite time convergent of TD:

Then

$$
\lim _{t \rightarrow t_{f}}\left|z_{1}-r\right|=0, \quad \lim _{t \rightarrow t_{f}}\left|z_{2}-\dot{r}\right|=0
$$

$$
e=z_{1}-x_{1}, \quad \dot{e}=\dot{r}-\dot{x}, \quad \dot{e}=\mathrm{z}_{2}-x_{2}
$$

where $t_{f}$ is the final time. Finally, the control law takes the following form:

$$
u=k_{p}\left(z_{1}-x_{2}\right)+k_{d}\left(z_{2}-x_{2}\right)
$$

This formula can be expanded for the $n$-th order systems to take the following form:

$$
u=\sum_{i=1}^{n} k_{i}\left(z_{i}-x_{i}\right)=\sum_{i=1}^{n} k_{i} e_{i}=K^{T} e
$$


Where $k_{1}=k_{p}, k_{2}=k_{d}$ and $k_{i}$ for $i>2$ is the weighting for the higher derivatives. Then the linear combination can be generalized to nonlinear form:

$$
u=\Psi(e)
$$

with $\Psi(0)=0$ since $u(0)=k_{p}(0)+k_{d}(0)=0$

\section{Definition:}

A function $\varphi: \boldsymbol{R} \rightarrow \boldsymbol{R}$ is said to be in sector $\left[k_{l}, k_{u}\right]$ if for all $q \in \boldsymbol{R}, p=\varphi(q)$ lies between $k_{l}$ and $k_{u}$

\section{Theorem 1:}

Recall the system in lemma (1). The system is stable with the nonlinear controller $\Psi(e)$ if $\Psi$ is sector bounded and odd function.

\section{Proof:}

Consider the following $n$-th order system which is controlled by the controller in lemma (1)

$$
x^{(n)}=f\left(x, \dot{x}, \ldots, x^{(n-1)}\right)+b u
$$

It is stable if the matrix $(A-b K)$ is stable.

$$
x^{(n)}=f\left(x, \dot{x}, \ldots, x^{(n-1)}\right)+b \Psi(e)
$$

The linearized state-space system is given as

$$
\dot{x}=A x+b \Psi(e)
$$

For $r=0$ then $z_{1}=z_{2}=z_{n}=0$

$$
\begin{aligned}
& e=-x \\
& \dot{x}=A x+b \Psi(-x) \\
& \dot{x}=A x-b \Psi(x)
\end{aligned}
$$

Choose a candidate Lyapunov function as

Then,

$$
V(x)=1 / 2 x T x
$$

$$
\begin{aligned}
& \dot{V}(x)=x^{T} \dot{x}=x^{T}(A x-b \Psi(x)) \\
& \dot{V}(x)=x^{T} A x-b x^{T} K x=x^{T}(A-b K) x
\end{aligned}
$$

It is clear that $\dot{V}(x)$ will be negative definite for stable $A-b K$.

\section{THE IMPROVED NONLINEAR STATE ERROR FEEDBACK (INLSEF) CONTROLLER}

\section{1) The Improved Nonlinear Tracking Differentiator} (INTD)

The improved nonlinear tracking differentiator based on the hyperbolic tangent function is given as follows:

$$
\begin{aligned}
& \dot{z}_{1}=z_{2} \\
& \dot{z}_{2}=-R^{2} \tanh \left(\frac{\beta z_{1}-(1-\alpha) v}{\gamma}\right)-R z_{2}
\end{aligned}
$$

where $z_{1}$ tracking the input $v$, and $z_{2}$ tracking the derivative of input $v$. the parameters $\alpha, \beta, \gamma$, and $R$ are the appropriate design parameters, where $0<\alpha<1, \beta>0, \gamma>0$, and $R>0$ [20].

\section{2) The Nonlinear Combination}

The nonlinear algorithm using sign and exponential functions has been developed as follows:

$$
u_{\text {INLSEF }}=\Psi(e)=k(e)^{T} f(e)+u_{\text {integrator }}
$$

Where $e$ is $n \times 1$ state error vector, defined as:

$$
e=\left[\begin{array}{lll}
e^{(0)} & \ldots . e^{(i)} \ldots . & e^{(n-1)}
\end{array}\right]^{T}
$$

$e^{(i)}$ is the $i$-th derivative of the state error, defined as:

$$
e^{(i)}=z^{(i)}-x^{(i)}
$$

$k(e)$ is the nonlinear gain function, defined as:

$$
\left.k(e)=\left[\begin{array}{c}
k(e)_{1} \\
\vdots \\
k(e)_{i} \\
\vdots \\
k(e)_{n}
\end{array}\right]=\left[\begin{array}{c}
\left(k_{11}+\frac{k_{12}}{1+\exp \left(\mu_{1}\left(e^{(0)}\right)^{2}\right)}\right) \\
\vdots \\
\left(k_{i 1}+\frac{k_{i 2}}{1+\exp \left(\mu_{n}\left(e^{(i-1)^{2}}\right)\right.}\right) \\
\vdots \\
\left.k_{n 1}+\frac{k_{n 2}}{1+\exp \left(\mu_{n}\left(e^{(n-1)}\right)^{2}\right)}\right)
\end{array}\right)\right]
$$

The coefficients $k_{i 1}, k_{i 2}$, and $\mu_{i}$ are positive constants. The benefit of the nonlinear gain term $k(e)_{i}$ is to make the nonlinear controller much more sensitive to small. When $e^{(i-1)}$ $=0, k(e)_{i}=k_{i 1}+k_{i 2} / 2$, while as $e^{(i-1)}$ goes large enough $k(e)_{i} \approx k_{i 1}$. For values of $e^{(i-1)}$ in between, The nonlinear gain $k(e)_{i}$ term is bounded in the sector [ $k i_{1}, k i_{1}+k i_{2} / 2$ ], see Fig. 3. The function $f(e)$ is the error function, defined as:

$f(e)=$

$\left[\begin{array}{lll}\left|e^{(0)}\right|^{\alpha_{1}} \operatorname{sign}(e) & \ldots\left|e^{(i)}\right|^{\alpha_{i}} \operatorname{sign}\left(e^{(i)}\right) \ldots & \left|e^{(n-1)}\right|^{\alpha_{n}} \operatorname{sign}\left(e^{(n)}\right)\end{array}\right]^{T}$

(4)

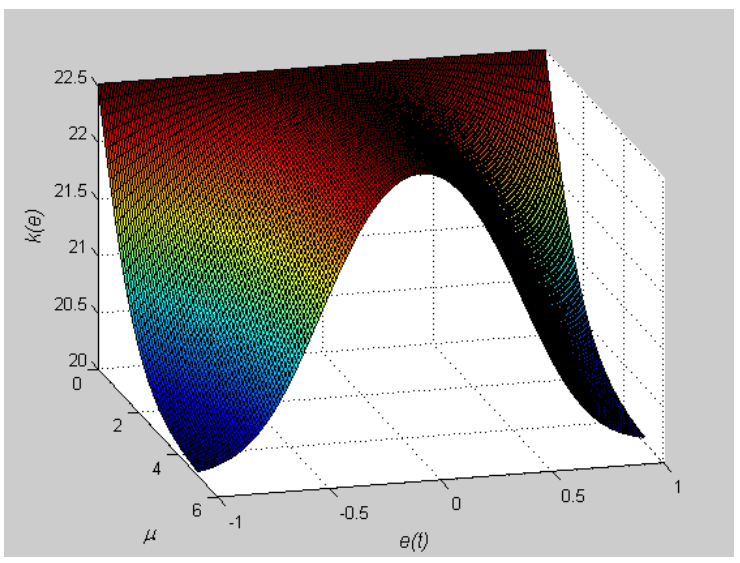

(a) 


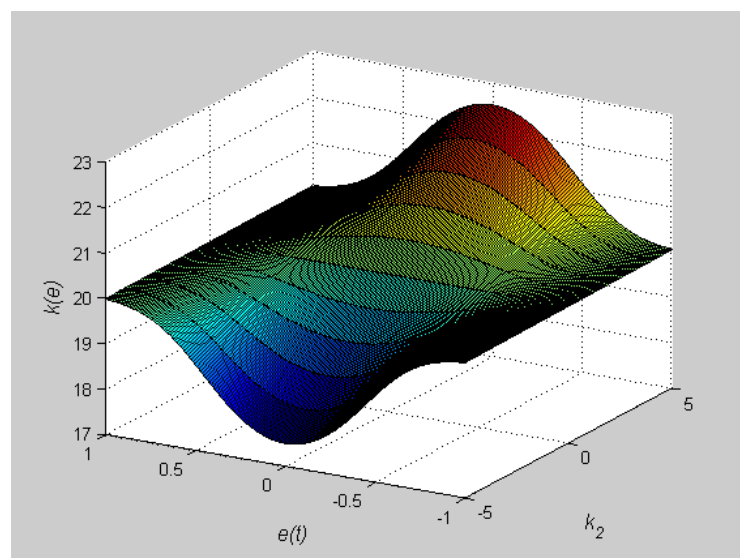

(b)

Fig. 3. Characteristics of the nonlinear gain function $k(e)$ for $\mathrm{n}=1$, (a) $\mathrm{k}_{\mathrm{i} 1}=20, \mathrm{k}_{\mathrm{i} 2}=5$ (b) $\mathrm{k}_{\mathrm{i} 1}=20, \mu=5$

Equation (4) shows significant features in the nonlinear term $|e|^{\alpha_{i}}$. For $\alpha_{i} \ll<1$, the term $|\mathrm{e}|^{\alpha_{1}}$ is rapidly switching its state as shown in Fig. 4.a. This feature makes the error function $f(e)$ is sensitive for small error values (as shown below). As $\alpha_{i}$ goes beyond 1, the nonlinear term becomes less sensitive for small variations in $\mathrm{e}$.

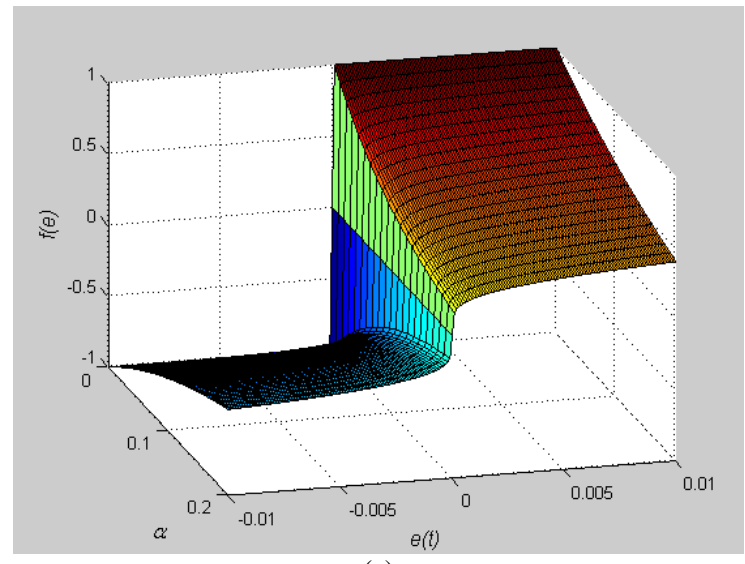

(a)

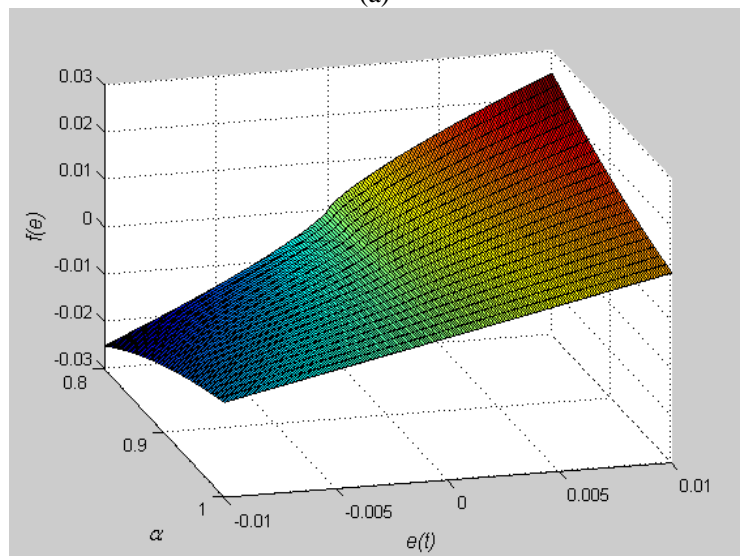

(b)

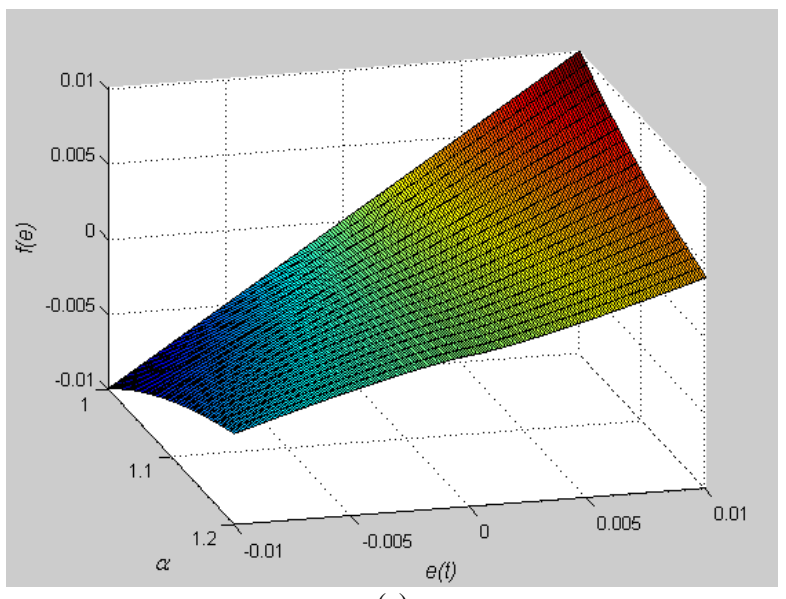

(c)

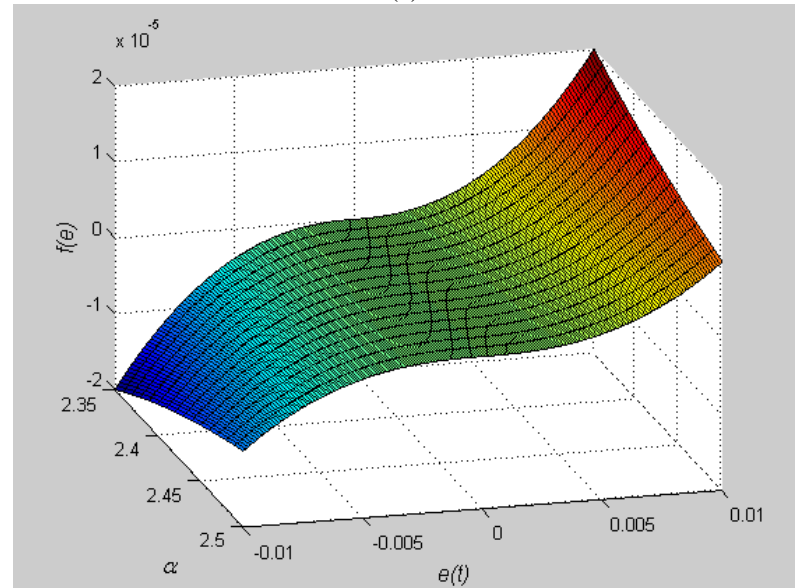

(d)

Fig. 4. Characteristics of the nonlinear error function $f(e)$

(a) $0 \leq \alpha \leq 0.2$ (b) $0.8 \leq \alpha \leq 1.0$ (c) $1.0 \leq \alpha \leq 1.2$ (d) $2.35 \leq \alpha \leq 2.5$

The integral action $u_{\text {integrator }}$ is introduced to eliminate the steady-state error. Sometimes it causes saturation problems (known as integrator windup) during transient response. On the other hand, when the error is small, the integral action $u_{\text {integrator }}$ has to take large values in order to eliminate steady-state error. For these reasons, the integral action should be designed carefully to act in both situations and to change gradually between minimum and maximum values. To achieve the above requirements the following form of the integral nonlinear action is used:

$$
u_{\text {integrator }}=\left(\left|\int e d t\right|^{\alpha} \operatorname{sign}\left(\int e d t\right)\right) \frac{k}{1+\exp \left(\mu\left(\int e d t\right)^{2}\right)}
$$

The coefficients $\alpha, k$, and $\mu$ are constants. Figure 5 shows the characteristics of the proposed integral control action. 


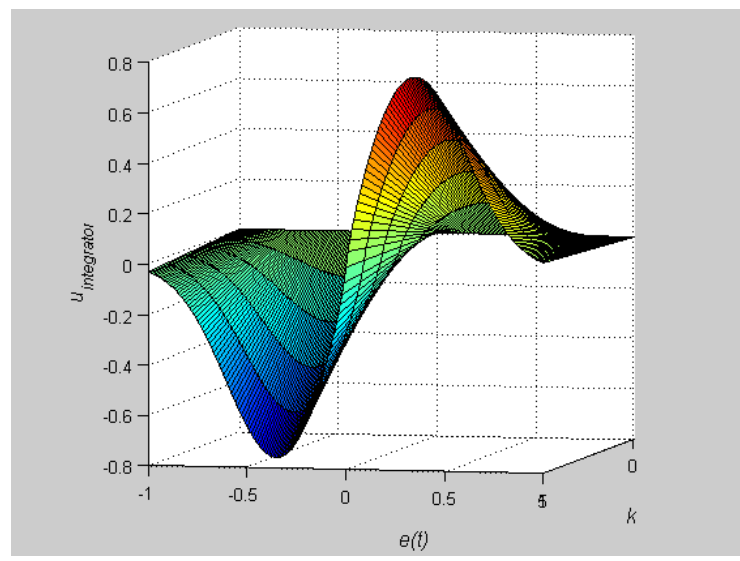

(a)

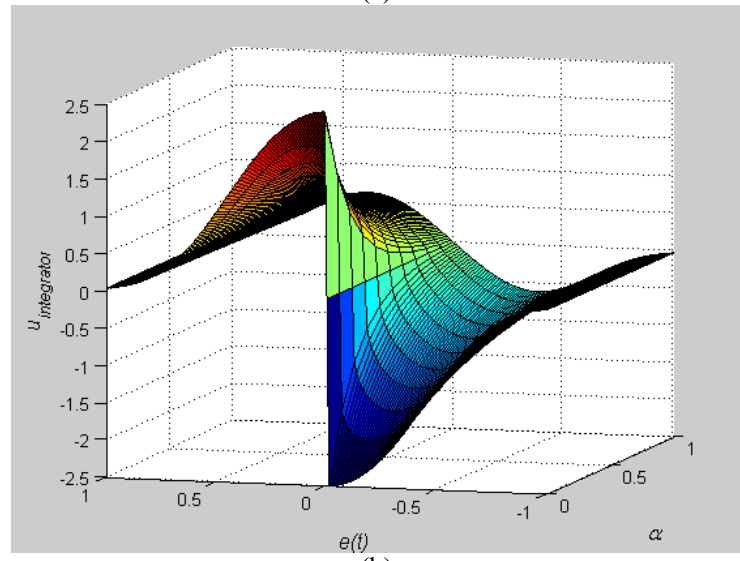

(b)

Fig. 5. Characteristics of the integral action, $u_{\text {integrator }}$. $\alpha=0.8, \mu=5$ (b) $k=5, \mu=5$

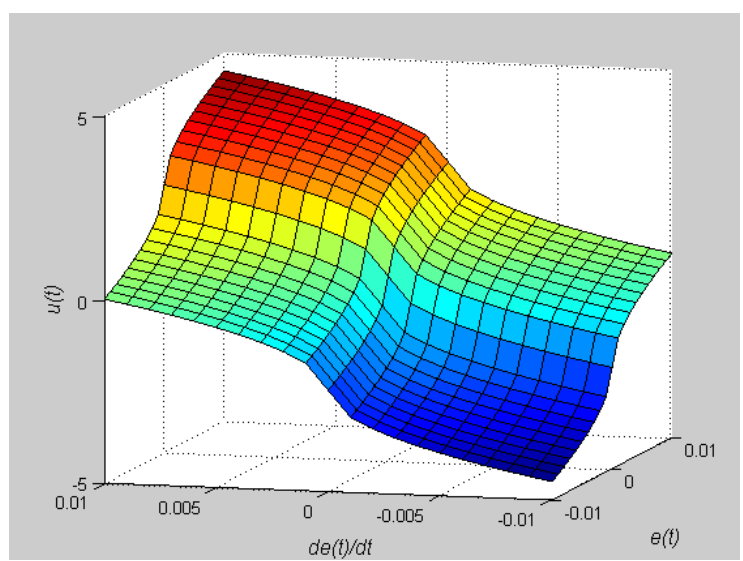

Fig. 6. The characteristic of the control signal $u$ with the following values of the parameters: $\mathrm{k} 11=\mathrm{k} 12=20, \mathrm{k} 12=\mathrm{k} 22=5, \alpha 1=\alpha 2=0.5, \mu 1=25, \mu 2=15, \delta=3$

The control signal $u$ can be limited using the nonlinear hyperbolic function $\tanh ($.$) in the form u=\delta \tanh \left(\frac{u_{I N L S E F}}{\delta}\right)$, where $u_{I N L S E F}$ is defined in (2). It has the following features:

1) The idea is that any real number $[-\infty, \infty]$ is mapped to a number between $[-\delta, \delta]$.

2) The $\tanh ($.$) function is symmetric about the origin, only$ zero-valued inputs are mapped to zero outputs.
3) The control action $u$ is limited via mapping but not clipped. Therefore, no strong harmonics in the high-frequency range.

Figure 6 shows the control signal $u$ applied to the controlled plant by considering the limiter stage.

\section{Nonlinear Systems Modeling AND Stability TeST OF THE CLOSED-LOOP SYSTEM}

1) The Nonlinear Mass-Spring-Damper Model

A simple nonlinear mass-spring-damper (MSD) mechanical system as shown in Figure 7. It is assumed that the stiffness coefficient of the spring, the damping coefficient of the damper, and the input term have nonlinearity or uncertainty [21, 22]:

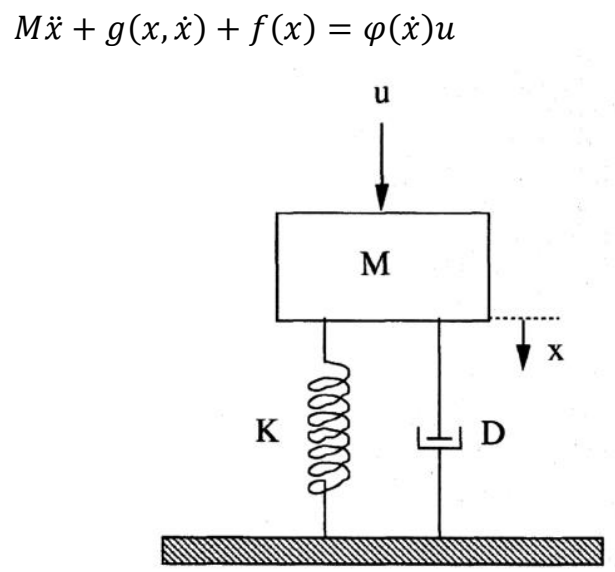

Fig. 7. The nonlinear mass spring damper model

where $M$ is the mass and $U$ is the input force, $f(x)$ is the nonlinear or uncertain term with respect to the spring, $g(x, \dot{x})$ is the nonlinear or uncertain term with respect to the damper, and $\varphi(\dot{\mathrm{x}})$ is the nonlinear term with respect to the input term. Assume that $g(x, \dot{x})=D\left(c_{1} x+c_{2} \dot{x}^{3}\right), f(x)=c_{3} x+c_{4} x^{3}$, and $\varphi(\dot{x})=1+c_{5} \dot{x}^{3}$, and furthermore, assume that $x \in$ $[-a a], \quad \dot{x} \in\left[\begin{array}{ll}-b & b\end{array}\right], \quad a, b>0$.

The above parameters are set as follows:

$\mathrm{M}=1.0, \quad \mathrm{D}=1.0, \mathrm{c}_{1}=0.01, \quad \mathrm{c}_{2}=0.1, \quad \mathrm{c}_{3}=0.01$, $\mathrm{c}_{4}=0.67, \mathrm{c}_{5}=0, \mathrm{a}=1.5, \mathrm{~b}=1.5$. Then, equation (6) can be rewritten as follows:

$$
\ddot{\mathrm{x}}=-0.1 \dot{\mathrm{x}}^{3}-0.02 \mathrm{x}-0.67 \mathrm{x}^{3}+\mathrm{u}
$$

The state space representation of the nonlinear mass spring dumper model is:

$$
\left.\begin{array}{l}
\dot{x}_{1}=x_{2} \\
\dot{x}_{2}=-0.1 x_{2}{ }^{3}-0.02 x_{1}-0.67 x_{1}{ }^{3}+u \\
y=x_{1}
\end{array}\right\}
$$

The stability of the nonlinear mass spring dumper system can be proven according to theory A.1

Where $r=0.1, \mathrm{~h}=k_{2}\left(x_{2}\right), s=(\rho+0.02), \rho \geq-0.02$, $\mathrm{t}=0.67$, $p=3$, and $q=3$

Then, the candidate Lyapunov function:

$$
V\left(x_{1}, x_{2}\right)=\frac{1}{2}(\rho+0.02) x_{1}{ }^{2}+\frac{1}{4} \times 0.67 x_{1}{ }^{4}+\frac{1}{2} x_{2}{ }^{2}
$$


Which leads to $\dot{V}=\left(\rho-k_{1}\left(x_{1}\right)\right) x_{1} x_{2}-0.1 x_{2}{ }^{4}-$ $k_{2}\left(x_{2}\right) x_{2}{ }^{2}$

For then the system to be globally asymptotically stable $(\dot{V}$ is negative definite)

Let $k_{1}\left(x_{1}\right)=\rho$ Then $k_{1}\left(x_{1}\right) \geq-0.02$

and $k_{2}\left(x_{2}\right)>0$

2) The Nonlinear Beam and Ball Model

The dynamic model of the beam and ball (BB) is considered, which is as follows:

$$
\left(\frac{J}{R^{2}}+m\right) \ddot{\gamma}+m g \sin \alpha-m \gamma \dot{\alpha}^{2}=0
$$

where $\alpha$ is the incline angle of the beam, $g$ is acceleration of gravity, $m$ is the ball's mass, $J$ is the ball's moment of inertia, $\gamma$ represents the ball's position on the beam, $R$ is the ball's radius. Assume that the movement of the ball is roll, and the friction is neglected. $\theta$ is the angle of the gear as well as the control input $u$. The state space representation of the model is:

$$
\begin{aligned}
& \dot{x}_{1}=x_{2} \\
& \dot{x}_{2}=\frac{1}{\left(\frac{J}{R^{2}}+m\right)}\left(-m g \sin \alpha+m x_{1} \dot{\alpha}^{2}\right) \\
& \alpha=\frac{d}{L} u \\
& y=x_{1}
\end{aligned}
$$

The model state space representation can be linearized near the zero angle and the following equation is obtained:

$$
\begin{aligned}
& \text { let } \mathrm{a}=\frac{-\mathrm{mg}\left(\frac{\mathrm{d}}{\mathrm{L}}\right)}{\left(\frac{\mathrm{J}}{\mathrm{R}^{2}}+\mathrm{m}\right)}, \text { then } \\
& \left.\begin{array}{l}
\dot{x}_{1}=x_{2} \\
\dot{x}_{2}=a u
\end{array}\right\}
\end{aligned}
$$

The proposed control law in this paper is given by:

$$
u=-k_{1}\left(x_{1}\right) x_{1}-k_{2}\left(x_{2}\right) x_{2}
$$

Then, the simplified state space representation of the closed loop system is given by:

$$
\left.\begin{array}{l}
\dot{x}_{1}=x_{2} \\
\dot{x}_{2}=a\left(-k_{1}\left(x_{1}\right) x_{1}-k_{2}\left(x_{2}\right) x_{2}\right)
\end{array}\right\}
$$

The candidate Lyapunov function is:

$$
v(x)=\frac{1}{2} x_{1}{ }^{2}+\frac{1}{2} x_{2}{ }^{2}
$$

The rate of change of $v(x)$ along the trajectory of (8)

$$
\begin{aligned}
& \dot{v}(x)=x_{1} \dot{x}_{1}+x_{2} \dot{x}_{2} \\
& \dot{v}(x)=x_{1} x_{2}+a x_{2}\left(-k_{1}\left(x_{1}\right) x_{1}-k_{2}\left(x_{2}\right) x_{2}\right) \\
& \dot{v}(x)=\left[\begin{array}{ll}
x_{1} & x_{2}
\end{array}\right]\left[\begin{array}{cc}
0 & 1 \\
-a k_{1}\left(x_{1}\right) & -a k_{2}\left(x_{2}\right)
\end{array}\right]\left[\begin{array}{l}
x_{1} \\
x_{2}
\end{array}\right]=x^{T} P x \\
& \text { Where } x^{T}=\left[\begin{array}{ll}
x_{1} & x_{2}
\end{array}\right] \text { and } P=\left[\begin{array}{cc}
0 & 1 \\
-a k_{1}\left(x_{1}\right) & -a k_{2}\left(x_{2}\right)
\end{array}\right]
\end{aligned}
$$

The characteristic equation of $\mathrm{P}$ can be defined as:

$$
|\lambda I-P|=0
$$

Then,

$$
\begin{aligned}
& \left|\left[\begin{array}{ll}
\lambda & 0 \\
0 & \lambda
\end{array}\right]-\left[\begin{array}{cc}
0 & 1 \\
-\mathrm{ak}_{1}\left(\mathrm{x}_{1}\right) & -\mathrm{ak}_{2}\left(\mathrm{x}_{2}\right)
\end{array}\right]\right|=0 \\
& \lambda^{2}+\mathrm{ak}_{2}\left(\mathrm{x}_{2}\right) \lambda+\mathrm{ak}_{1}\left(\mathrm{x}_{1}\right)=0
\end{aligned}
$$

For asymptotically stable system, the following conditions must satisfy:

$$
\mathrm{k}_{2}\left(\mathrm{x}_{2}\right)>0 \text { and } \mathrm{k}_{1}\left(\mathrm{x}_{1}\right)>0
$$

\section{NUMERICAL SIMULATION}

The numerical simulations are done by using MATLAB $® /$ Simulink $®$ ODE45 solver for the models with continuous states as shown in Figure 8. This Runge-Kutta ODE45 solver is a fifth-order method that performs a fourthorder estimate of the error.

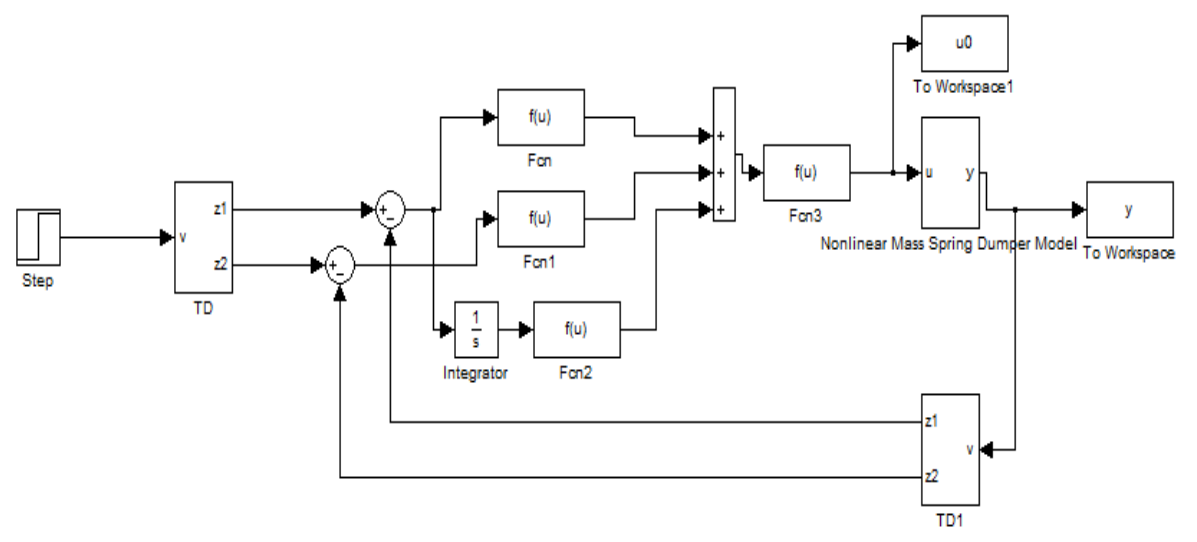

(a) 


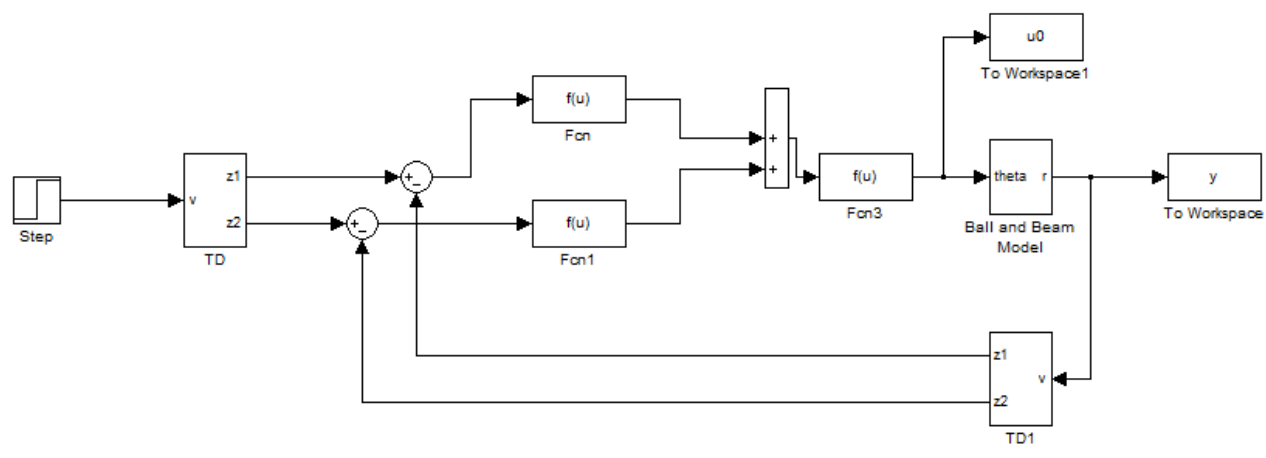

(b)

Fig. 8. The Simulink ${ }^{\circledR}$ models for the INLSEF controller for, (a) the nonlinear mass spring dumper plant, (b) the beam and ball plant

The parameters of the beam and ball model and the improved tracking differentiator are listed in tables 1and 2, respectively. This numerical simulations include comparing the proposed INSEF controller, with a group of five different controllers described in Table 3. The parameters of the controllers to be simulated in this work are listed in tables 4-9. Fig. 9 shows the simulated responses for the output signal $y(t)$ and the control input signal $u(t)$ for the six controllers include the proposed one for the nonlinear Mass-Spring-Damper. The same comparison results are obtained for the nonlinear Balland-Beam as shown in Fig. 10. The results (including the performance indices defined in table 10) from the numerical simulation of the controlled model are shown in tables 11,12.

TABLE I. THE PARAMETERS OF THE BEAM AND BALL MODEL

\begin{tabular}{|c|c|}
\hline Parameter & Value \\
\hline$m$ & 0.1110 \\
\hline$R$ & 0.0150 \\
\hline$g$ & -9.8000 \\
\hline$L$ & 1.0000 \\
\hline$d$ & 0.0300 \\
\hline$J$ & $\frac{2 m R^{2}}{5}$ \\
\hline
\end{tabular}

TABLE II. THE PARAMETERS OF THE ITD MODEL

\begin{tabular}{|c|c|c|}
\hline parameter & Value for the MSD & Value for the BB \\
\hline$\alpha$ & 0.9789 & 1.9778 \\
\hline$\beta$ & 5.5872 & 2.6256 \\
\hline$\gamma$ & 8.3864 & 3.3667 \\
\hline$R$ & 26.5005 & 3.3796 \\
\hline
\end{tabular}

TABLE III. THE TESTED AND THE PROPOSED CONTROLLERS

\begin{tabular}{|c|c|}
\hline $\begin{array}{c}\text { Controller } \\
\text { Label }\end{array}$ & Control Law \\
\hline $\operatorname{Han}[6][23][24]$ & $\begin{array}{l}u=\beta_{1} \operatorname{fal}\left(e, \alpha_{1}, \delta_{1}\right)+\beta_{2} f a l\left(\dot{e}, \alpha_{2}, \delta_{2}\right) \\
+\beta_{3} f a l\left(\int e d t, \alpha_{3}, \delta_{3}\right) \\
\operatorname{fal}(e, \alpha, \delta)=\left\{\begin{array}{cl}\frac{e}{\delta^{1-\alpha}} & |x| \leq \delta \\
|e|^{\alpha} \operatorname{sign}(e) & |x| \geq \delta\end{array}\right.\end{array}$ \\
\hline Huang[7] [25] & $\begin{aligned} u=K_{p} e^{\alpha_{p}} \operatorname{sign}(e)+ & K_{d} \dot{e}^{\alpha_{d}} \operatorname{sign}(\dot{e}) \\
& +K_{i}\left(\int e d t\right)^{\alpha_{i}} \operatorname{sign}\left(\int e d t\right)\end{aligned}$ \\
\hline Linear & $u=K_{p} e+K_{d} \dot{e}+K_{i} \int e d t$ \\
\hline Marroquin[5] & $\begin{aligned} u=K_{0}\left(1+b_{0}|e|\right) e+ & K_{1}\left(1+b_{1}|\dot{e}|\right) \dot{e} \\
& +K_{2}\left(1+b_{2}\left|\int e d t\right|\right) \int e d t\end{aligned}$ \\
\hline $\mathrm{Su}[8][4]$ & $\begin{array}{l}u=k_{p} k(e) e+k_{d} k(e) \dot{e}+k_{i} \int k(e) e d t \\
k(e)=\frac{e^{k_{0} e}+e^{-k_{0} e}}{2} \\
e=\left\{\begin{array}{cc}e \quad & |e| \leq e_{\max } \\
e_{\max } \operatorname{sgn}(e) & |e|>e_{\max }\end{array}\right.\end{array}$ \\
\hline INLSEF & $\begin{array}{l}u_{\text {INLSEF }}=u_{1}+u_{2}+u_{\text {integrator }} \\
u_{1}=\left(k_{11}+\frac{k_{12}}{1+\exp \left(\mu_{1} e^{2}\right)}\right)|e|^{\alpha 1} \operatorname{sign}(e) \\
u_{2}=\left(k_{21}+\frac{k_{22}}{1+\exp \left(\mu_{2} \dot{e}^{2}\right)}\right)|\dot{e}|^{\alpha 2} \operatorname{sign}(\dot{e}) \\
u_{\text {integrator }} \\
=\frac{k_{3}}{1+\exp \left(\mu_{3} \int e d t^{2}\right)}\left|\int e d t\right|^{\alpha 3} \operatorname{sign}\left(\int e d t\right) \\
u=\delta \tanh \left(\frac{u_{I N L S E F}}{\delta}\right)\end{array}$ \\
\hline
\end{tabular}


TABLE IV. PARAMETERS FOR HAN CONTROLLER

\begin{tabular}{|c|c|c|}
\hline Parameter & Value for the MSD & Value for the BB \\
\hline$\delta 1$ & 0.0486 & 0.6136 \\
\hline$\alpha 1$ & 0.1698 & 0.35946 \\
\hline$\beta 1$ & 0.7310 & 0.2816 \\
\hline$\delta 2$ & 0.1029 & 0.1709 \\
\hline$\alpha 2$ & 0.0192 & 1.8072 \\
\hline$\beta 2$ & 0.7951 & 1.10563 \\
\hline$\delta 3$ & 0.9062 & Not Available \\
\hline$\alpha 3$ & 1.4548 & Not Available \\
\hline$\beta 0$ & 0.0675 & Not Available \\
\hline
\end{tabular}

TABLE V. PARAMETERS FOR HUANG CONTROLLER

\begin{tabular}{|c|c|c|}
\hline Parameter & Value for the MSD & Value for the BB \\
\hline$\alpha_{p}$ & 0.7426 & 0.6553 \\
\hline $\mathrm{K}_{\mathrm{p}}$ & 1.0001 & 0.1723 \\
\hline$\alpha_{\mathrm{d}}$ & 0.8100 & 0.7933 \\
\hline $\mathrm{K}_{\mathrm{d}}$ & 1.9962 & 1.7724 \\
\hline$\alpha_{\mathrm{i}}$ & 1.8388 & Not Available \\
\hline $\mathrm{K}_{\mathrm{i}}$ & 1.0643 & Not Available \\
\hline
\end{tabular}

TABLE VI. PARAMETERS FOR THE LINEAR CONTROLLER

\begin{tabular}{|c|c|c|}
\hline Parameter & Value for the MSD & Value for the BB \\
\hline $\mathrm{Kp}$ & 5.9702 & 1.37670 \\
\hline $\mathrm{Kd}$ & 2.8908 & 3.9704 \\
\hline $\mathrm{Ki}$ & 0.3990 & Not Available \\
\hline
\end{tabular}

TABLE VII. PARAMETERS FOR MARROQUIN CONTROLLER

\begin{tabular}{|c|c|c|}
\hline Parameter & Value for the MSD & Value for the BB \\
\hline b0 & 0.0161 & 0.0548 \\
\hline K0 & 5.8419 & 1.3482 \\
\hline b1 & 0.0182 & 0.0633 \\
\hline K1 & 2.7905 & 3.8506 \\
\hline b2 & 0.0367 & Not Available \\
\hline K2 & 0.3114 & Not Available \\
\hline
\end{tabular}

TABLE VIII. PARAMETERS FOR SU CONTROLLER

\begin{tabular}{|c|c|c|}
\hline Parameter & Value for the MSD & Value for the BB \\
\hline $\mathrm{K} 0$ & 0.0424 & 0.1112 \\
\hline $\mathrm{Kp}$ & 6.7315 & 0.0032 \\
\hline $\mathrm{Kd}$ & 3.0049 & 3.1001 \\
\hline $\mathrm{Ki}$ & 1.7583 & Not Available \\
\hline emax & 4.0040 & 0.1884 \\
\hline
\end{tabular}

TABLE IX. PARAMETERS FOR INSEF CONTROLLER

\begin{tabular}{|c|c|c|}
\hline Parameter & Value for the MSD & Value for the BB \\
\hline $\mathrm{k} 11$ & 14.3805 & 2.2772 \\
\hline $\mathrm{k} 12$ & 3.0109 & 1.5979 \\
\hline $\mathrm{k} 21$ & 7.3156 & 2.7004 \\
\hline $\mathrm{k} 22$ & 0.9606 & 1.5868 \\
\hline $\mathrm{k} 31$ & 7.1760 & Not Available \\
\hline$\delta$ & 0.7999 & 0.5072 \\
\hline$\mu 1$ & 3.5365 & 2.5266 \\
\hline$\mu 2$ & 3.8318 & 0.2970 \\
\hline$\mu 3$ & 4.1307 & Not Available \\
\hline$\alpha 1$ & 0.8573 & 1.4245 \\
\hline$\alpha 2$ & 0.9618 & 0.9303 \\
\hline$\alpha 3$ & 2.2723 & Not Available \\
\hline
\end{tabular}

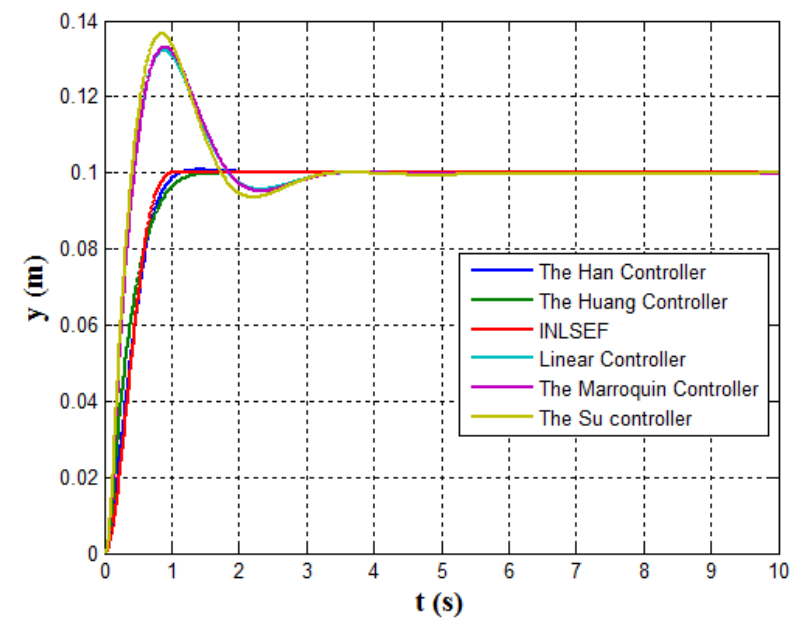

(a)

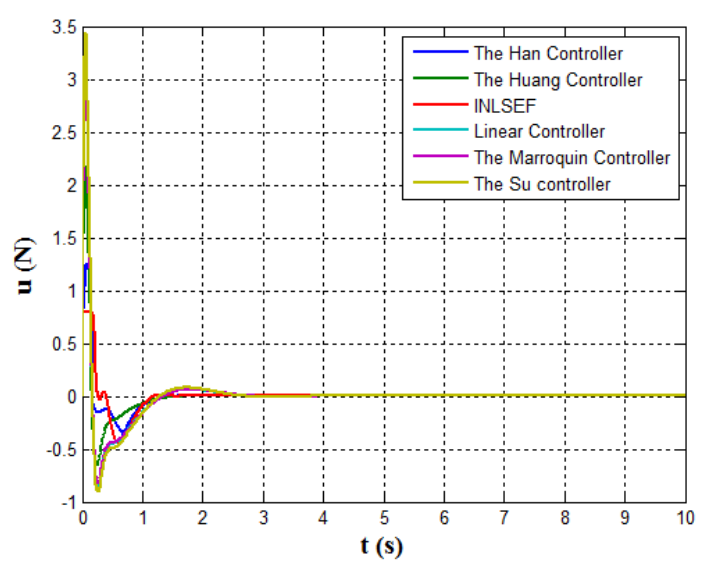

(b)

Fig. 9. The time response for $0.1 \mathrm{u}(\mathrm{t})$ reference input applied to the closed loop system for the nonlinear mass spring dumper plant, (a) The output signal (b) The control signal

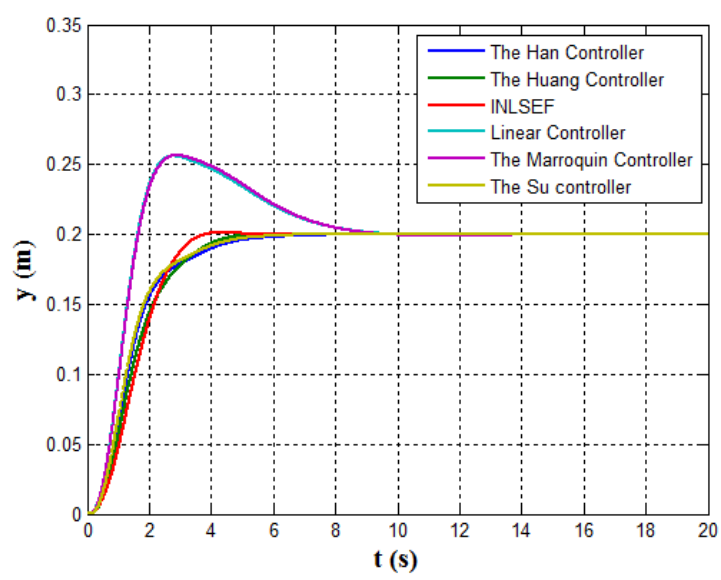

(a) 


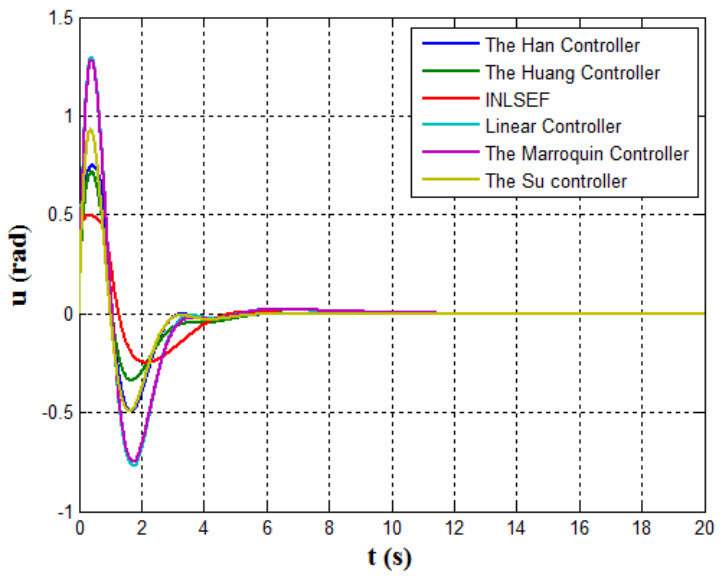

(b)

Fig. 10. The time response for $0.2 \mathrm{u}(\mathrm{t})$ reference input applied to the closed loop system for the nonlinear beam and ball plant, (a) The output signal (b) The control signal

TABlE X. The Mathematical Representation of the CALCulated PERFORMANCE INDICES

\begin{tabular}{|c|l|c|}
\hline $\begin{array}{c}\text { Performance } \\
\text { Index }\end{array}$ & \multicolumn{1}{|c|}{ Description } & \multicolumn{1}{c|}{$\begin{array}{c}\text { Mathematical } \\
\text { Representation }\end{array}$} \\
\hline ITAE & $\begin{array}{l}\text { Integrated time absolute } \\
\text { error }\end{array}$ & $\int_{0}^{\mathrm{tf}} \mathrm{t}|\mathrm{e}(\mathrm{t})| \mathrm{dt}$ \\
\hline USQR & Controller energy & $\int_{0}^{\mathrm{tf}} \mathrm{u}(\mathrm{t})^{2} \mathrm{dt}$ \\
\hline UABS & $\begin{array}{l}\text { Integrated absolute of } \\
\text { the control signal }\end{array}$ & $\int_{0}^{\mathrm{tf}}|\mathrm{u}(\mathrm{t})| \mathrm{dt}$ \\
\hline
\end{tabular}

The objective performance index (OPI) is a quantitative measure of the performance of a system and is chosen so that emphasis is given to the important system specifications. The OPI is represented in this work as:

$$
\text { OPI }=w_{0} \times \frac{\text { ITAE }}{N_{0}}+w_{1} \times \frac{\text { UABS }}{N_{1}}+w_{2} \times \frac{\text { USQR }}{N_{2}}
$$

Where $\mathrm{w}_{0}=0.6, \mathrm{w}_{1}=\mathrm{w}_{2}=0.2, \mathrm{~N}_{0}=0.1, \mathrm{~N}_{1}=0.2$, and $\mathrm{N}_{2}=0.1$

For the nonlinear mass spring dumper, let the initial value of the internal states of the tracking differentiator are zeros. At $t=0$ the error $r-y$ is equal to 0.1 . Because of the delay inherited by the integrators of the tracking [20], the tracking differentiator tracks the input signal and rises up for a short time (from 0 to $0.675 \mathrm{~s}$ ). The large error value $e_{1}=\mathrm{e}=z_{1}-x_{1}$ causes a very large positive controller signal $u_{1}$, because of the gain function $k\left(e_{1}\right)$ with the large values of the gain parameters $\left(k_{11}, k_{12}\right)$ and error function $f\left(e_{1}\right)$ with the parameter $\alpha$ less than 1.The same behavior for the error signal $e_{2}$. This control signal $u_{\text {INLSEF }}$ is limited by the $\tanh ($.) function stage to the maximum positive output which is equal to the value of the parameter $\delta$. The controller signal $u$ forces the plant to achieve a good jump to approach the required set point $(0.1 \mathrm{~m})$. After the zero crossing point from positive to negative values of $e_{2}=\dot{e}$, the relatively large negative and sharp positive slop control signal $\mathrm{u}_{2}$ reduce the overshoot and bring the plant output back to the predetermined set point and stay there fast which in turn reduces the settling time.

TABLE XI. THE NUMERICAL SIMULATION RESULTS FOR THE NONLINEAR MASS SPRING DUMPER PLANT

\begin{tabular}{|c|c|c|c|c|c|c|}
\hline & $\begin{array}{c}\text { Han } \\
\text { Controller }\end{array}$ & $\begin{array}{c}\text { Huang } \\
\text { Controller }\end{array}$ & linear Controller & $\begin{array}{c}\text { Marroquin } \\
\text { Controller }\end{array}$ & $\begin{array}{c}\text { Su } \\
\text { Controller }\end{array}$ & INSEF \\
\hline ITAE & 0.0138 & 0.0116 & 0.0528 & 0.0566 & 0.0549 & 0.0108 \\
\hline USQR & 0.2926 & 0.4927 & 1.0377 & 0.9957 & 1.1524 & 0.1930 \\
\hline UABS & 0.4484 & 0.5019 & 0.7909 & 0.7827 & 0.8503 & 0.3845 \\
\hline OPI & 1.8615 & 2.1814 & 6.0353 & 6.1678 & 6.4507 & 1.4161 \\
\hline
\end{tabular}

TABLE XII. THE NUMERICAL SIMULATION RESULTS FOR THE BEAM AND BALL PLANT

\begin{tabular}{|c|c|c|c|c|c|c|}
\hline & $\begin{array}{c}\text { Han } \\
\text { Controller }\end{array}$ & $\begin{array}{c}\text { Huang } \\
\text { Controller }\end{array}$ & linear Controller & $\begin{array}{c}\text { Marroquin } \\
\text { Controller }\end{array}$ & $\begin{array}{c}\text { Su } \\
\text { Controller }\end{array}$ & INSEF \\
\hline ITAE & 0.3930 & 0.3749 & 0.9804 & 1.0180 & 0.4132 & 0.3345 \\
\hline USQR & 0.5846 & 0.4043 & 1.4101 & 1.3597 & 0.6277 & 0.2949 \\
\hline UABS & 1.1911 & 1.0443 & 1.8805 & 1.8649 & 1.1811 & 0.9632 \\
\hline OPI & 25.9351 & 24.3483 & 63.5226 & 65.6649 & 27.2281 & 21.6197 \\
\hline
\end{tabular}




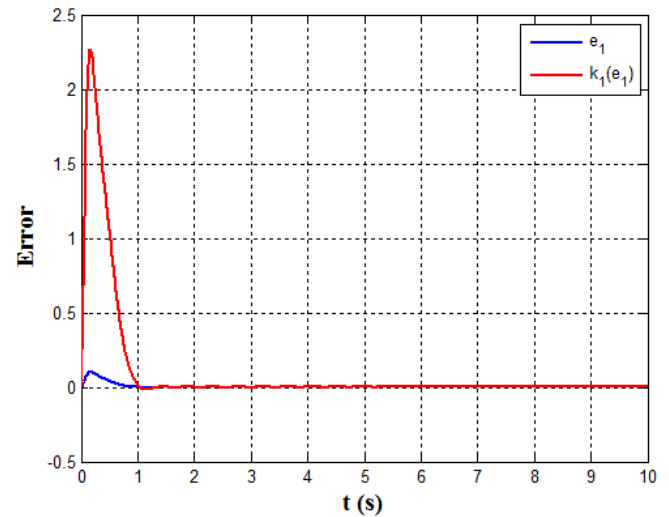

(a)

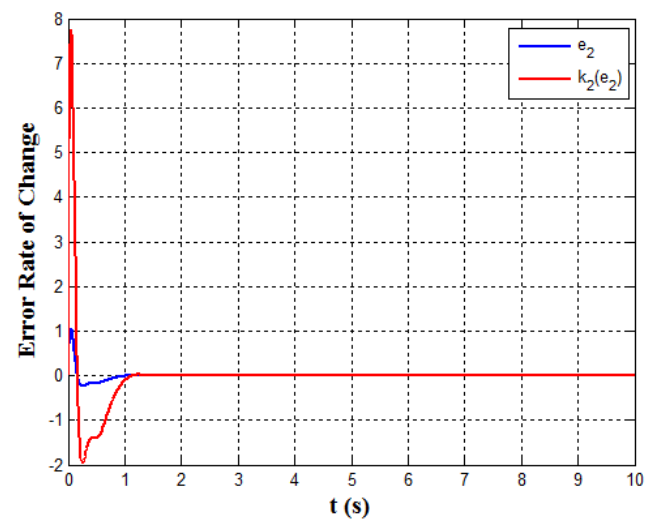

(b)

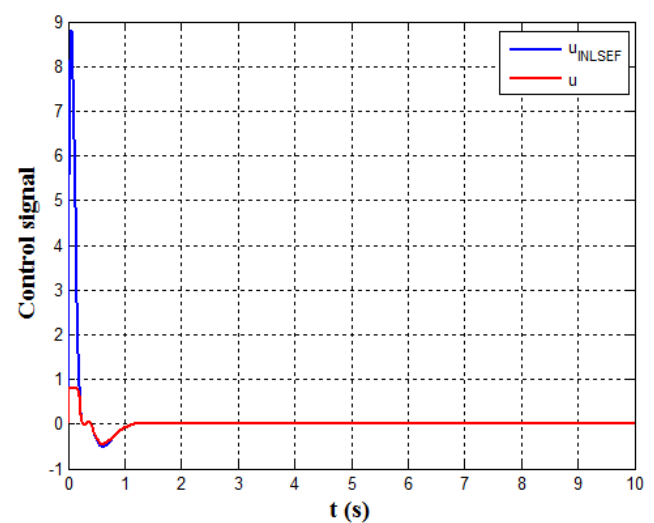

(c)

Fig. 11. The components of the control signal. (a)The nonlinear gain functin,

$k_{1}\left(e_{1}\right)$ (b) The nonlinear gain functin, $k_{2}\left(e_{2}\right)$, (c) The control action, $u$

The proposed nonlinearities stated in this paper and included in the proposed INLSEF controller lead to an improvement on the performance of the classical state feedback controller, where the OPI of the proposed controller is approximately reduced by $71.2 \%$ as compared to the classical linear PID controller for both tested models. The performance indices of the proposed controller are near to indices values for both Han [6][23][24] and Huange [7][25] controllers. This closeness is due to the common term $|\mathrm{e}|^{\alpha} \operatorname{sign}(\mathrm{e})$ included in the structure of these controllers. Moreover, the proposed controller further reduces the values of the performance indices because of the nonlinear gain function $k(e)$, which enhances the transient behavior of the system response. The proposed INLSEF shows a significant reduction in the energy relative to all other controllers. The energy saving feature can be noticed from the USQR performance index. This decrease in the energy is associated with the $\tanh ($. limiting function in the proposed controller.

\section{CONCLUSION}

In this paper an improvement has been introduced to the behavior of the traditional PID controller by suggesting an improved nonlinear state error feedback controller (INLSEF) which consists of a sector-bounded nonlinear gain function, a nonlinear tracking differentiators, and the linear PID control structure. The proposed nonlinear controller has been tested on two nonlinear models, the Mass-spring, and Ball-and-Beam models. A precise tracking differentiator has been designed to produce an accurate differential signal in the existence of noise. The INLSEF controller shows a minimum ITAE index among other nonlinear controllers selected from literature. The INLSEF controller shows a fast and smooth output in response to the set point reference. Additionally, it satisfies the time domain specifications. To avoid actuator saturation and to reduce the energy of the control signal, a mapping via hyperbolic function has been introduced which acts as a limiter for the control signal, this is indicated from the tables of comparisons by adopting the indices USQR and UABS as measures. By adopting Lyapunov technique, the stability of the closed-loop system with the new INLSEF controller has been tested and verified for both models. The results were produced by the numerical simulation show that the proposed controller improves the transient response and the stability of the selected models. Further work will introduce an optimization tool as an addition for design of the suggested INLSEF controller.

\section{APPENDIX A}

\section{Theory A.1:}

Consider the control system, which is represented by the following differential equation: $\ddot{y}+r \dot{y}^{p}+h \dot{y}+s y+t y q=0$, where $r, h, s$, and $t$ are positive parameters and $p$, and $q$ are odd positive constants. The stability of this system can be checked by using the following Lyapunov function:

$V\left(x_{1}, x_{2}\right)=\frac{1}{2} s x_{1}{ }^{2}+\frac{1}{q+1} \times t x_{1}{ }^{q+1}+\frac{1}{2} x_{2}{ }^{2}$ Where $x_{1}=y$ and $x_{2}=\dot{y}$

which is radially unbounded function i.e. $V\left(x_{1}, x_{2}\right) \rightarrow \infty$ as $\left\|\left(x_{1}, x_{2}\right)\right\| \rightarrow \infty$,

and positive definite function i.e. $V\left(x_{1}, x_{2}\right) \geq 0$ for all $\left(x_{1}, x_{2}\right) \neq(0,0)$. And $V(0,0)=0$

\section{Proof:}

Since, $x_{2}=\dot{y}$

Then, $\dot{x}_{2}=\ddot{y}=-r \dot{y}^{p}-h \dot{y}-s y-t y^{q}$

The state-space representation of the control system is:

$$
\begin{aligned}
& \dot{x}_{1}=x_{2} \\
& \dot{x}_{2}=-s x_{1}-t x_{1}{ }^{q}-h x_{2}-r x_{2}{ }^{p}
\end{aligned}
$$


Since $\dot{V}=\frac{\partial V}{\partial x_{1}} \dot{x}_{1}+\frac{\partial V}{\partial x_{2}} \dot{x}_{2}$

Then,

$\dot{V}=\left(s x_{1}+t x_{1}{ }^{q}\right) \dot{x}_{1}+x_{2} \dot{x}_{2}=\left(s x_{1}+t x_{1}{ }^{q}\right) x_{2}+$

$x_{2}\left(-s x_{1}-t x_{1}^{q}-h x_{2}-r x_{2}{ }^{p}\right)$

And $\dot{V}=\left(s x_{1} x_{2}+t x_{1}{ }^{q} x_{2}\right)+\left(-s x_{1} x_{2}-t x_{1}{ }^{q} x_{2}-h x_{2}{ }^{2}-\right.$ $\left.r x_{2}^{p+1}\right)$

Final, $\dot{V}=-h x_{2}{ }^{2}-r x_{2}{ }^{p+1}$

Since $s$ is negative definite with respect to $\mathrm{x}_{1}, \mathrm{x}_{2}$, then the system is globally asymptotically stable.

\section{ACKNOWLEGMENT}

The authors appreciate the electrical engineering department laboratories for direct help and support to finish this research.

\section{REFERENCES}

[1] R. R. BENREZKI, M. TADJINE, F. YACEF and O. KERMIA, 'Passive Fault Tolerant Control of Quad rotor UAV Using a Nonlinear PID', IEEE Conference on Robotics and Biometrics, 2015.

[2] R. Cajo, W. Agila, 'Evaluation of algorithms for linear and nonlinear PID control for Twin Rotor MIMO System', IEEE 2015 Asia-Pacific Conference on Computer Aided System Engineering,2015.

[3] D. Naso, F. Cupertino, and B. Turchiano, 'NPID and Adaptive Approximation Control of Motion Systems with Friction', IEEE Transactions on Control Systems Technology, VOL. 20, NO. 1, January 2012.

[4] S. Najib Sy Salim,M.F. Rahmat, A. A. M. Faudzi, N.H.Sunar,Z. H. Ismail,Sharatul Izah Samsudin, 'Tracking Performance and Disturbance Rejection of Pneumatic Actuator System', Control Conference (ASCC),pp.1-6,June, 2013.

[5] G. Marroquin, William L. Luyben, 'Experimental Evaluation of Nonlinear Cascade Controllers for Batch Reactors', Industrial and Engineering chemistry Fundamentals, 11 (4), pp 552-556,1972,.

[6] L. Congying, W. Shixing, Y. Zhi , Y. Jinyong, W. Huijin, 'Antiwindup Nonlinear PID Controller Design and Its Application to Winged Missile Control System', Proceedings of the 27th Chinese Control Conference, July, 2008.

[7] Y.L.Kang, G.B.Shrestha and T.T.Lie, 'Application of an NLPID controller on a UPFC to improve transient stability of a power system', IEE Pror.-Gener,. Transm. Distrib., Vol. 148. No. 6, Novemher 2001.

[8] Y.X. Su, Dong Sun .Y. Duan, 'Design of an enhanced nonlinear PID controller', Elsevier Ed., Mechatronics , Pp.1005-1024, 2005.

[9] K. Premkumar, B.V. Manikandan, "Fuzzy PID supervised online ANFIS based speed controller for brushless dc motor," Neurocomputing, Vol. 157, pp. 76-90,2015.

[10] N.K. Arun, B.M. Mohan, Neethu Kuruvilla, "A Nonlinear Fuzzy PID Controller via Algebraic Product AND-Maximum OR-Larsen Product Inference," IFAC-PapersOnLine, Vol. 49, Iss.1, Pp. 543-548,2016.
[11] H. Moradi, H. Setayesh, A. Alasty, " PID-Fuzzy control of air handling units in the presence of uncertainty," International Journal of Thermal Sciences, Vol.109, pp. 123-135, November 2016.

[12] A. Zamani, S. M. Barakati, S. Yousofi-Darmian, "Design of a fractional order PID controller using GBMO algorithm for load-frequency control with governor saturation consideration," ISA Transactions, Vol. 64, pp. 56-66, September 2016.

[13] M. Z. Al Faiz and S. A. Sadeq, "Particle Swarm Optimization Based Fuzzy-Neural Like PID Controller for TCP/AQM Router," Intelligent Control and Automation, pp. 71-77,2012.

[14] C. JIA, T. BAI, X. SHAN, F. CUI, S. XU, “Cloud Neural Fuzzy PID Hybrid Integrated Algorithm of Flatness Control,"Journal of Iron and Steel Research, International, Vol. 21, Iss.6, June, pp. 559-564, 2014.

[15] B. Xing; L. Yu; Z. Zhou, "Composite single neural PID controller based on fuzzy self-tuning gain and RBF network identification," The 26th Chinese Control and Decision Conference,2014.

[16] M. L. Zegai; M. Bendjebbar; K. Belhadri; M. L Doumbia; B. Hamane; P. M. Koumba "Direct torque control of Induction Motor based on artificial neural networks speed control using MRAS and neural PID controller," Electrical Power and Energy Conference (EPEC), pp. 320 325, 2015 .

[17] B. Saidi; M. Amairi; S. Najar; M. Aoun, "Multi-objective optimization based design of fractional PID controller," 12th International MultiConference on Systems, Signals \& Devices (SSD),pp. 1-6, 2015.

[18] P. Shah, S. Agashe , "Review of fractional PID controller," Mechatronics, vol. 38, pp. 29-41,September 2016.

[19] D. Bai; C. Wang, “ Parameter calibration and simulation of fractional PID controller for hydraulic servo system," 2016 Chinese Control and Decision Conference (CCDC), pp. 1704 - 1708, 2016.

[20] I. K. Ibraheem,W. R. AbdulAdheem, "On the Improved Nonlinear Tracking Differentiator based Nonlinear PID Controller Design, "International Journal of Advanced Computer Science and Applications(IJACSA), Volume 7 Issue 10, 2016.

[21] Z. Xiu, W. Wang, 'A Novel Nonlinear PID Controller Designed By Takagi-Sugeno Fuzzy Model', Proceedings of the 6th World Congress on Intelligent Control and Automation, June 21 - 23, Dalian, China, 2006.

[22] K. Tanaka, H. Wang, 'Robust Stabilization of a Class of Uncertain Nonlinear Systems via Fuzzy Control: Quadratic Stabilizability, Hinfinity Control Theory, and Linear Matrix Inequalities', IEEE Transactions on Fuzzy Systems, Vol. 4, No 1, February 1996.

[23] L. Ma, F. Lin, X. You, Trillion Q. Zheng, 'Nonlinear PID Control of Three-Phase Pulse Width Modulation Rectifier',Proceedings of the 7th World Congress on Intelligent Control and Automation June 25 - 27, 2008.

[24] D. Haibin, W. Daobo, and Y. Xiufen, 'Realization of nonlinear PID with feed-forward controller for 3-DOF flight simulator and hardwarein-the-loop simulation', Journal of Systems Engineering and Electronics Vol. 19, No. 2, pp.342-345,2008.

[25] H. Huang, J. Han, 'Nonlinear PID Controller and Its Applications in Power Plants', IEEE International Conference on Power System Technology, pages 1513 - 1517 vol.3, 2002. 